\title{
Basic Tutorial on Sliding Mode Control in Speed Control of DC-motor
}

\author{
$1^{\text {st }}$ Hari Maghfiroh \\ Dept. Electrical Engineering \\ Universitas Sebelas Maret \\ Surakarta, Indonesia \\ hari.maghfiroh@gmail.com \\ $3^{\text {rd }}$ Musyaffa' Ahmad \\ Dept. Electrical Engineering \\ Universitas Sebelas Maret \\ Surakarta, Indonesia \\ mus_ahmad@student.uns.ac.id
}

\author{
$2^{\text {nd }}$ A. Sujono \\ Dept. Electrical Engineering \\ Universitas Sebelas Maret \\ Surakarta, Indonesia \\ agus.sjn.te16@gmail.com \\ $4^{\text {th }}$ Chico Hermanu Brillianto Apribowo \\ Dept. Electrical Engineering \\ Universitas Sebelas Maret \\ Surakarta, Indonesia \\ chico@ft.uns.ac.id
}

\begin{abstract}
One technology to support production speed is electric motors with high performance, efficiency, dynamic speed and good speed responses. DC motors are one type of electric motor which is used in the industry. Sliding Mode Control (SMC) is the robust nonlinear control. The basic theory regarding SMC is presented. The SMC design which is implemented is the speed control of the DC motor is analyzed. The controller is implemented in simulation using MATLAB / Simulink environment. The step response and signal tracking test unit are carried out. The results show that SMC has a better performance compare to PID which is faster settling time and no overshoot and undershoot.
\end{abstract}

Keywords—railway, traction motor, motor control, MRAS

\section{INTRODUCTION}

One of the technologies used to accelerate the production process in the industry is an electric motor. Electric motor based on the electric current is divided into two, namely DC motors and AC motors. DC motors were first discovered and are still widely used today because of the ease in the control system. However, DC motors require more expensive maintenance costs than AC motors because of the brush that can wear out. Electric motor applications in the industrial world include electric cars, robotic actuators, paper machines and home applications [1].

PID is one of the classic control methods that are still widely used. Based on [2][3] 90\% of industries still use PID because of the advantages of being simple and applicable. However, one disadvantage of this method is that performance decreases if the plant is non-linear [4]. Sliding Mode Control (SMC) is one controller that can handle plant nonlinearity conditions. R.K. Munje et.al.[5] said that the advantages of SMC are robustness, ability to deal with non-linear systems, time-varying systems, it can be designed for fast dynamic responses and good abilities over the wide range.

DC motor will have electrical parameters changes as the temperature increase, current, and voltage fluctuations, timevarying loading conditions, driving and operating conditions [6]. These changes are making the DC motor has non-linear characteristics. Therefore, the non-linear control method is needed. In this research, the SMC method will be applied in speed control of DC motor. Classical PID is used to compare the performance of SMC.

This paper is organized as follows. Section II present the theoretical review of SMC which mentioned before. In section III, design of SMC for speed control of DC motor is presented. In section IV, the simulation results are discussed. Finally, the conclusion is in section $\mathrm{V}$.

\section{SLIDING MODE CONTROL}

The SMC works by bringing the state from the system to the sliding surface and then to the central point, as illustrated in Figure 1 (a). Next Figure 1 (b) shows the switching of the control signal tracking the sliding surface to the origin. Sliding surface is a condition where the switching function $(s)$ is zero $(s=0)$. On the top and bottom of the sliding surface, there is a limiting switching value, $\pm \Delta$. If a state $x(t)$ is $x(t)>\Delta$ then switching will be off, otherwise if $\mathrm{x}(\mathrm{t})<-\Delta$ then switching will be on. System reach sliding surface by making transition between stable and unstable trajectories and error converge to zero in sliding surface [7]. The aim of the SMC is that the output of the system is to track to the desired reference and to produce control signals which make minimum tracking error.

The control signal in the SMC consists of two parts, namely in reaching mode and sliding mode. Reaching mode is to bring the state of the system to a sliding surface, switching control $\left(u_{s w}\right)$ is required. Furthermore, in the sliding mode state, there is an equivalent control $\left(u_{e q}\right)$ to keep the state system stable. The sliding mode control signal can be written as equation (1), while switching control defined as (2). Figure 2 shows the SMC diagram where the control signal consists of equivalent control and switching control.

$$
\begin{aligned}
& u_{S M C}(t)=u_{e q}+u_{s w} \\
& u_{s w}=K \operatorname{sgn}(s)
\end{aligned}
$$

where $K>0$ is selected sufficiently large. The larger value of $K$, the faster the trajectory converges to the sliding surface. 


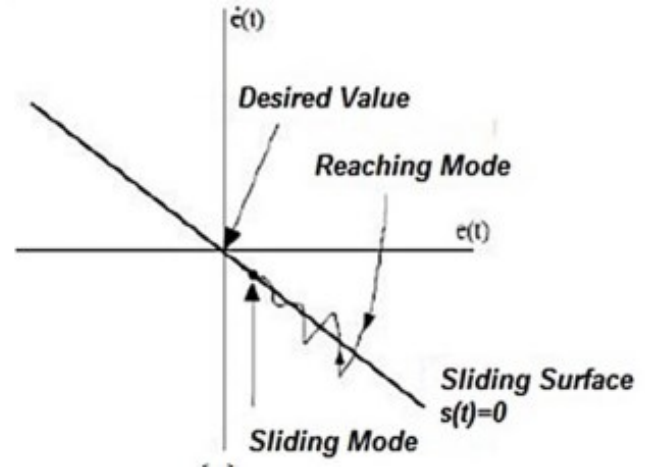

(a)Phase portrait of sliding mode control

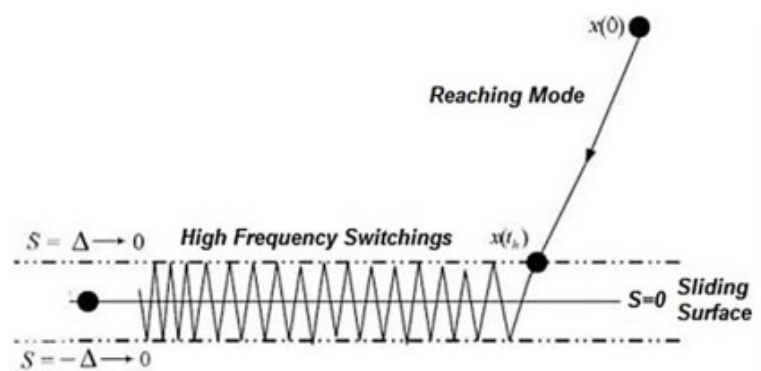

(b) Sliding surface, reaching mode and high frequency switching

Fig. 1. Sliding Mode Control (SMC) process [7]

SMC has the disadvantage of switching from discontinuous control. There are many methods to reduce chattering. One can consider pseudo sliding with smooth control action [8].

$$
u_{s w}=K \frac{s}{|s|+\delta}
$$

where $\delta$ is a small tuning scalar called as tuning parameter to reduce chattering.

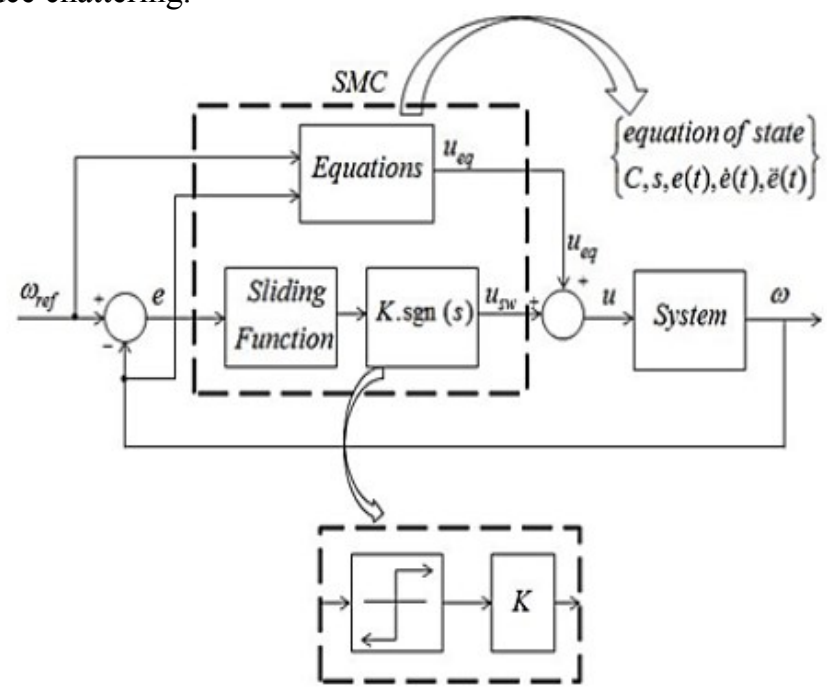

Fig. 2. Diagram block of Sliding Mode Control (SMC) [7]

\section{SPEED CONTROL OF DC MOTOR}

\section{A. DC Motor Model}

There is a lot of DC motor model which can be found in references as in [9][10]. In this research, the real DC motor is modeled using MATLAB System Identification. The inputoutput which is voltage and speed is taken using Arduino data logger. The data are processed using MATLAB and the secondorder transfer function of the DC motor is found as in (4)[11]. Figure 1 shows the DC motor and controller as the plant.

$$
\frac{\omega(s)}{V(s)}=\frac{138.5}{s^{2}+1.48 s+12.81}
$$

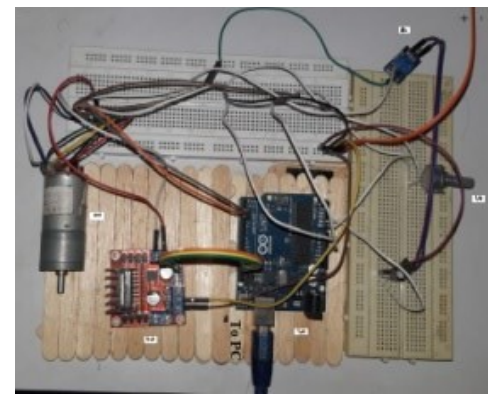

Fig. 3. DC motor as the plant

\section{B. SMC Controller Design}

In time domain, equation (4) can be written as

$$
\ddot{\omega}(t)+1.48 \dot{\omega}(t)+12.81 \omega=138.5 V(t)
$$

Now consider

$$
x_{1}=\omega(t) \text { and } u=V(t)
$$

Then the system can be converted into the following canonical form

$$
\begin{aligned}
& \dot{x}_{1}=x_{2} \\
& \dot{x}_{2}=\ddot{\omega}=-1.48 x_{2}-12.81 x_{1}+138.5 u \\
& y=x_{1}
\end{aligned}
$$

Now, the equivalent control and switching control can be designed

- Switching function

$$
\begin{aligned}
& s=C e+\dot{e}=C\left(\omega_{r}-\omega\right)+\left(\dot{\omega}_{r}-\dot{\omega}\right) \\
& \dot{s}=C\left(\dot{\omega}_{r}-\dot{\omega}\right)+\left(\ddot{\omega}_{r}-\ddot{\omega}\right)
\end{aligned}
$$

where $\omega_{r}$ is the speed reference and $C>0$ is performance parameter which guaranteed the stability of the system [12]. On sliding surface 


$$
s=0 \rightarrow \dot{s}=0
$$

- Equivalent control can be found by substituting equation (8) into equation (11) when $\dot{s}=0$ as follow

$$
\begin{gathered}
C\left(\dot{\omega}_{r}-\dot{\omega}\right)+\ddot{\omega}_{r}-\left(-1.48 x_{2}-12.81 x_{1}+138.5 u\right)=0 \\
C\left(\dot{\omega}_{r}-\dot{\omega}\right)+\ddot{\omega}_{r}+1.48 \dot{\omega}+12.81 \omega-138.5 u=0
\end{gathered}
$$

Since the derivative of reference signal of set point is zero, equation (14) became

$$
\begin{aligned}
& 138.5 u=12.81 \omega+(1.48-C) \dot{\omega} \\
& u_{e q}=u=\frac{1}{138.5}(12.81 \omega+(1.48-C) \dot{\omega})
\end{aligned}
$$

- To eliminate the chattering effect, switching control in equation (3) is used. Therefore, the final controller signal for SMC is as follow

$$
u_{S M C}=\frac{1}{138.5}(12.81 \omega+(1.48-C) \dot{\omega})+K \frac{S}{|S|+\delta}
$$

Simulink model of the control system shown in Fig.4. Fig. 4(a) is the Simulink model for the PID model that will be compared to the SMC performance. While the parameters' value of PID is chosen by trial and error. While Fig. 4(b) is the Simulink model for SMC control.

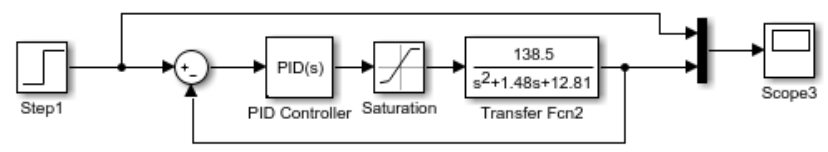

(a) Simulink model for PID control

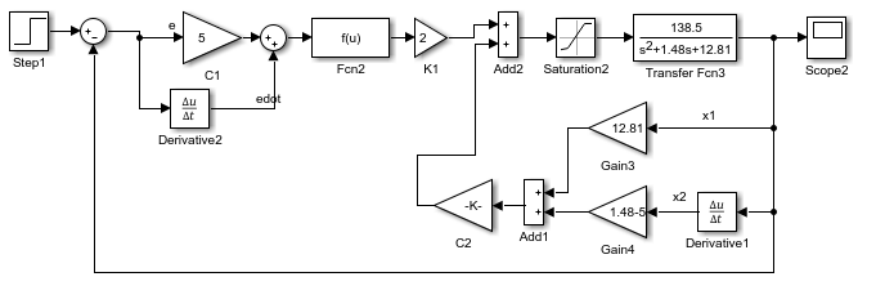

(b) Simulink model for SMC control

Fig. 4. Simulink model of control system

\section{RESUlt AND Discustion}

\section{A. Unit Step Response}

The unit step response is the basic testing to know the performance of the controller including settling time and overshoot. Fig. 5 shows the step response of the system which is PID and SMC control. It clearly is shown that PID has a faster rise time. However, its settling time is lower due to oscillation before reaching the steady state. On the other hand, SMC has a lower rise time without oscillation and reach steady-state condition faster than PID. Both controller response has zero steady-state error. Detailed controller performance parameters can be seen in Table 1. It clearly is seen that the PID response has a big overshoot and undershoot while SMC did not have.

table I. Performance for Unit Step Response

\begin{tabular}{cccc}
\hline $\begin{array}{c}\text { Control } \\
\text { method }\end{array}$ & $\begin{array}{c}\text { Settling time } \\
\text { (second) }\end{array}$ & $\begin{array}{c}\text { Maximum \% } \\
\text { overshoot (OS) }\end{array}$ & $\begin{array}{c}\text { Maximum \% } \\
\text { undershoot }\end{array}$ \\
\hline \hline PID & 1.3 & 9 & 9 \\
SMC & 0.8 & 0 & 0 \\
\hline
\end{tabular}

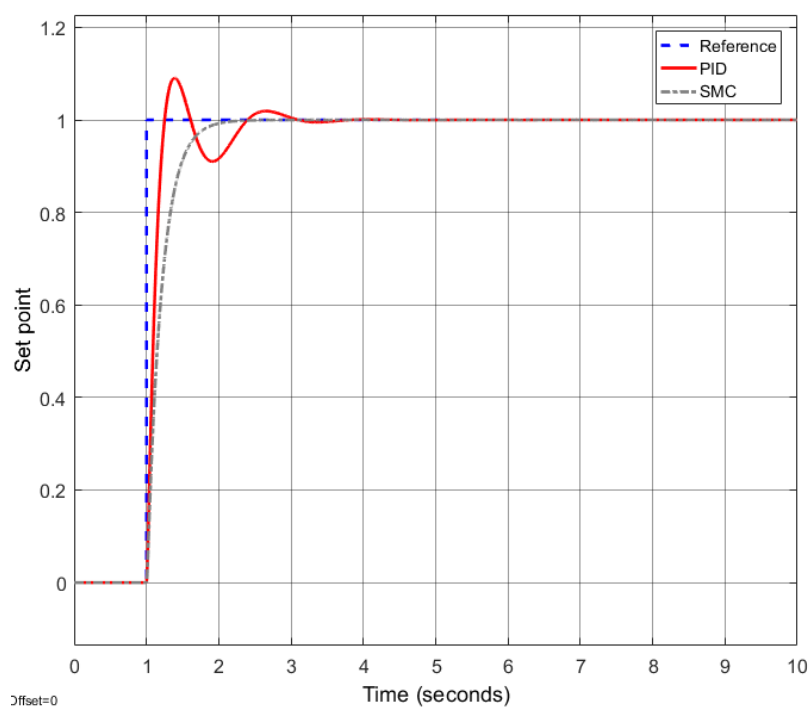

Fig. 5. Performance of unit step response

\section{B. Signal Tracking}

The next test is signal tracking. In this test, setpoint changes are given to the system. Fig. 6 show the result of the test. It can be seen, the same result as unit step response, PID has a faster rise time. However, it oscillates before reaching steady-state condition and makes settling time become longer. When the set point reduces, PID also has oscillated before steady, while SMC has not. Detail controller parameters can be seen in Table 2 for the second set point because the first set point is the same as the unit step response, Table 1. It also can be seen, when set point decreases, SMC did not have both overshoot and undershoot. On the other hand, PID still has a big overshoot and undershoot.

TABLE II. Performance for Signal Tracking $2^{\text {ND }}$ Set Point

\begin{tabular}{cccc}
\hline $\begin{array}{c}\text { Control } \\
\text { method }\end{array}$ & $\begin{array}{c}\text { Settling time } \\
\text { (second) }\end{array}$ & $\begin{array}{c}\text { Maximum } \\
\text { overshoot (OS) }\end{array}$ & $\begin{array}{c}\text { Maximum } \\
\text { undershoot }\end{array}$ \\
\hline \hline PID & 1.27 & 5 & 6.6 \\
SMC & 0.60 & 0 & 0 \\
\hline
\end{tabular}

\section{CONCLUSION}

SMC is the robust non-linear control. The basic theory regarding SMC is already discussed. The SMC implementation is speed control of DC motor also clearly explained. The SMC design implemented in simulation using MATLAB/ Simulink environment. A unit step response and signal tracking test are 
carried out. The result shown that SMC has better performance compare to PID which is faster settling time and no overshoot and undershoot.

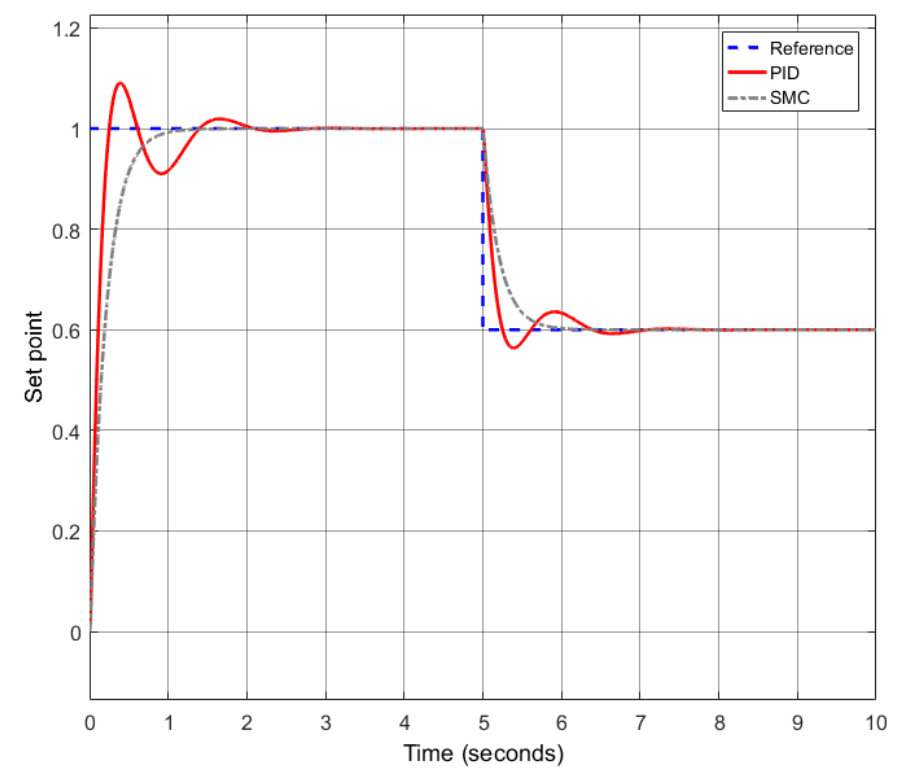

Fig. 6. Performance of signal tracking

\section{REFERENCES}

[1] D. Kumar and M. S.J., "Design and Performance Evaluation of Robust SMC schemes for Speed Control of DC Motor," in 2014 IEEE International Conference on Advanced Communication Control and Computing Technologies(ICACCCT), 2014, vol. 2, no. 1, pp. 88-92.

[2] S. M. Rakhtala and E. S. Roudbari, "Application of PEM Fuel Cell for Stand-alone Based on a Fuzzy PID Control," Bull. Electr. Eng. Informatics, vol. 5, no. 1, pp. 45-61, 2016.

[3] K. H. Ang, G. Chong, S. Member, and Y. Li, "PID Control System Analysis , Design , and Technology," IEEE Trans. Control Syst. Technol., vol. 13, no. 4, pp. 559-576, 2005.

[4] H. Maghfiroh, O. Wahyunggoro, A. I. Cahyadi, and S. Praptodiyono, "PID-Hybrid Tuning to Improve Control Performance in Speed Control of DC Motor Base on PLC," in 3rd ICA, 2013, no. August 2014, pp. 233 238.

[5] R. K. Munje, M. R. Roda, and B. . Kushare, "Speed Control of DC Motor Using PI and SMC," in IPEC 2010, 2010, pp. 945-950.

[6] S. V Ambesange, S. Y. Kamble, and D. S. More, "Application of Sliding Mode Control for the Speed Control of DC Motor Drives," in 2013 IEEE Internatioanal Conference on Control Application (CCA), 2013, no. 1, pp. 832-836.

[7] E. H. Dursun and A. Durdu, "Speed Control of a DC Motor with Variable Load Using Sliding Mode Control," Int. J. Comput. Electr. Eng., vol. 8, no. 3, pp. 219-226, 2016.

[8] U. Ch, K. Babu, and K. Amaresh, "Sliding Mode Speed Control of a DC Motor," in 2011 International Conference on Communication Systems and Network Technologies, 2011, no. June, pp. 387-391.

[9] H. Maghfiroh, A. Ataka, O. Wahyunggoro, and A. I. Cahyadi, "Optimal Energy Control of DC Motor Speed Control : Comparative Study," in 2013 IC3INA, 2013, no. July 2014.

[10] P. Ghalimath and S. S. Sankeswari, "Speed control of DC motor using sliding mode control approach," IOSR J. Electr. Electron. Eng., vol. 10, no. 4, pp. 17-22, 2015.

[11] A. G. Alfano, H. Maghfiroh, I. Iftadi, C. H. B. A, and F. Adriyanto, "Modelling and Simulation of DC Motor Speed Control Using Fuzzy-PID Algorithm," J. Electr. Electron. Information, Commun. Technol., vol. 1, no. 1, pp. 13-18, 2019.

[12] G. Murtaza, "CONTROL OF DC MOTORS USING SLIDING MODE," in 2019 9th International Bhuran Conference on Applied Sciences and Technology (IBCAST), 2012, pp. 37-42. 